\title{
Tratamento cirúrgico do ameloblastoma: revisão atualizada da literatura
}

\author{
Marilia Gerhardt de Oliveira ${ }^{1}$ \\ Otacílio Luiz Chagas Júnior ${ }^{2}$ \\ Ana Cláudia Lustosa Pereira ${ }^{2}$ \\ Letícia Kirst Post ${ }^{2}$
}

\begin{abstract}
Resumo
O tratamento do ameloblastoma é uma das principais controvérsias da Cirurgia e Traumatologia Buco-maxilo-facial, devido ao grande número de desinformaçôes existentes na literatura, como também ao grande número de condutas instituídas. Dessa forma, foi realizada uma pesquisa bibliográfica no site www.pubmed.gov, sendo selecionados os artigos publicados em 2006 relacionados ao tratamento cirúrgico do ameloblastoma, tendo como objetivo verificar, discutir e elucidar tais condutas. Baseando-se nos dados obtidos, conclui-se que existem inúmeras controvérsias a respeito do tratamento ideal, embora a maioria dos autores concorde que fatores fundamentais, tais como o tipo e a idade do paciente, são determinantes para a escolha da conduta cirúrgica a ser adotada.
\end{abstract}

Palavras-chave: Ameloblastoma - Tratamento; Neoplasia odontogênica.

\section{INTRODUÇÃO}

O ameloblastoma é a neoplasia odontogênica mais comum que afeta os maxilares ${ }^{1,2}$. É um tumor benigno agressivo, de origem epitelial incerta. Sugere-se que seja proveniente do órgão reduzido do esmalte, remanescente da lâmina dentária, e do revestimento epitelial de cistos odontogênicos, ou ainda de células epiteliais da camada basal da mucosa oral. ${ }^{1,2,3}$. Clinicamente, pode ser classificado em três tipos: sólido ou multicístico, unicístico e periférico. ${ }^{1,2,3,4}$

O tratamento cirúrgico do ameloblastoma representa um protótipo para o tratamento dos tumores da região maxilo-facial em geral ${ }^{5}$, e pode ser dividido em conservador e radical, o que constitui uma das maiores controvérsias da cirurgia e traumatologia buco-maxilo-facial.

O objetivo deste trabalho foi verificar e discutir os artigos publicados em 2006 sobre o tratamento cirúrgico do ameloblastoma.

\section{REVISÃO DE LITERATURA}

Foi realizada pesquisa bibliográfica no site www.pubmed.gov, digitando-se como palavraschave, na busca, "ameloblastoma" e "treatment". Somente foram selecionados os artigos publicados em 2006 que traziam uma contribuição ao tratamento cirúrgico.

\footnotetext{
${ }^{1}$ Professora Doutora do Programa de Pós-Graduação em Cirurgia e Traumatologia Bucomaxilofacial Faculdade de Odontologia - PUCRS.

${ }^{2}$ Doutorando do Programa de Pós-Graduação em Cirurgia e Traumatologia Bucomaxilofacial -Faculdade de Odontologia - PUCRS.
}

Correspondência para / Correspondence to: Marília Oliveira

Av. Ipiranga, 6681 - Prédio 06, sala 209

CEP: 90.610-001 Porto Alegre -RS - Brazil

Tel.: (51) 3320-3500. E-mail:mogerhardt@yahoo.com.br 
Carlson e Marx ${ }^{5}$ realizaram um estudo com a finalidade de fornecer suporte para o manejo cirúrgico curativo primário da variante sólida ou multicística do ameloblastoma. Sendo assim, o sucesso e as falhas de relatos previamente publicados foram citados, bem como as experiências pessoais individuais desses autores em controlar esse tumor. Afirmam que os termos "conservador" e "radical" são incorretos, pois acreditam que a terapia conservadora seja uma contradição, pois nunca foi provado que a cirurgia conservadora é terapia com chance de cura. Em adição, radical é uma palavra muito forte para descrever uma ressecção curativa para essa neoplasia agressiva.

Ghandhi e colaboradores ${ }^{1}$ investigaram se existiam diferenças significantes no modo de apresentação, tratamento, e resultados de pacientes que se apresentavam com diagnóstico primário de ameloblastoma em Glasgow, Escócia, e São Francisco, CA, Estados Unidos. Concluíram que o modo de apresentação, diagnóstico, e tratamento do ameloblastoma foi notavelmente similar em Glasgow e em São Francisco. A taxa de recorrência, seguida de enucleação local e curetagem, foi inaceitavelmente alta, e isso incluiu os casos de ameloblastoma unicístico, os quais deveriam ter sido tratados mais agressivamente do que recomendado no passado.

$\mathrm{Na}$ tentativa de estabelecer orientações no tratamento cirúrgico com base nos padrôes de crescimento dos ameloblastomas em relação à possibilidade de infiltração do osso cortical, nervo alveolar inferior, periósteo, e tecidos moles subjacentes, Gortzak e colaboradores 6 realizaram um trabalho em que 5 pacientes com ameloblastomas mandibulares volumosos foram tratados pela cirurgia radical. Sugeriram que, quando o tumor estiver radiologicamente a 1 $\mathrm{cm}$ da borda inferior da mandíbula, uma ressecção continuada é mandatória, com uma abordagem conservadora do nervo alveolar inferior, e ainda não indicando a remoção de um excesso de tecido mole perimandibular.

Um novo algoritmo, com o objetivo de auxiliar os cirurgiōes a desenvolverem um protocolo racional de diagnóstico e estabelecerem uma terapia cirúrgica conservadora efetiva nos pacientes com ameloblastoma mandibular, foi realizado por Sammartino e colaboradores ${ }^{3}$. Esses autores afirmam que, quando mais cedo detectadas e as recorrências são pequenas e periféricas pela grande quantidade de osso normal não envolvido, então é possível tratá-las com ressecção radical, minimizando, dessa maneira, o risco de recorrência adicional e evitando problemas cosméticos e funcionais severos.

Sachs ${ }^{4}$ afirmou que, até serem desenvolvidas objetivamente orientações terapêuticas, a responsabilidade clínica permanece quanto a formular um plano de tratamento cirúrgico que seja individualizado e centrado no paciente, e não baseado em um algoritmo cirúrgico arbitrário. Propôs uma abordagem conservadora, ainda definitiva, para alguns ameloblastomas, o que chamou de excisão cirúrgica com ostectomia periférica.

Gomes e colaboradores ${ }^{2}$ realizaram extensa revisão de literatura, verificando as atuais abordagens cirúrgicas para o tratamento do ameloblastoma. Identificaram uma tendência recente da comunidade científica em realizar procedimentos menos invasivos, inclusive para a variante sólida ou multicística.

\section{DISCUSSÃO}

Atualmente, apesar de a Odontologia ser baseada em evidências, não há consenso quanto à abordagem cirúrgica para o tratamento curativo do ameloblastoma, perceptível ao se analisarem criteriosamente todos os artigos publicados em 2006, nos quais existem idéias conflitantes.

O ameloblastoma é uma patologia benigna, de comportamento biológico agressivo, que confunde patologistas e cirurgiōes. Dentre as modalidades de tratamento conservador, encontramos a enucleação, enucleação + curetagem, enucleação + crioterapia, excisão cirúrgica com ostectomia periférica, e excisão cirúrgica com ostectomia periférica + crioterapia. E o tratamento radical, a ablação com margem de segurança de 1,0 a $2,0 \mathrm{~cm}^{1-4}$.

Algoritmos e protocolos de conduta são importantes ${ }^{3}$, mas falham quanto à 
individualização do tratamento. Realmente, como afirma Sachs ${ }^{4}$, o tratamento cirúrgico deve ser individualizado, pois se acredita que, além do subtipo do ameloblastoma e seu comportamento biológico, os ditames terapêuticos cirúrgicos são o diagnóstico, a idade do paciente, o tamanho da lesão e a localização anatômica.

Verifica-se que a grande falha do tratamento conservador é a proservação a longo prazo dos pacientes. O trabalho de Ghandhi e colaboradores ${ }^{1}$ revela que mesmo os ameloblastomas unicísticos, que são menos invasivos que os multicísticos, devem ter uma atenção maior, recomendando uma abordagem mais agressiva.

Há trabalhos em que o tratamento ablativo foi instituído e em que houve recidiva no enxerto reabilitador. Provavelmente, isso se deveu a falha $\mathrm{da}$ abordagem cirúrgica. Por isso, é de boa técnica fazer uso da radiografia da peça no trans-cirúrgico (FIGURA 1), bem como
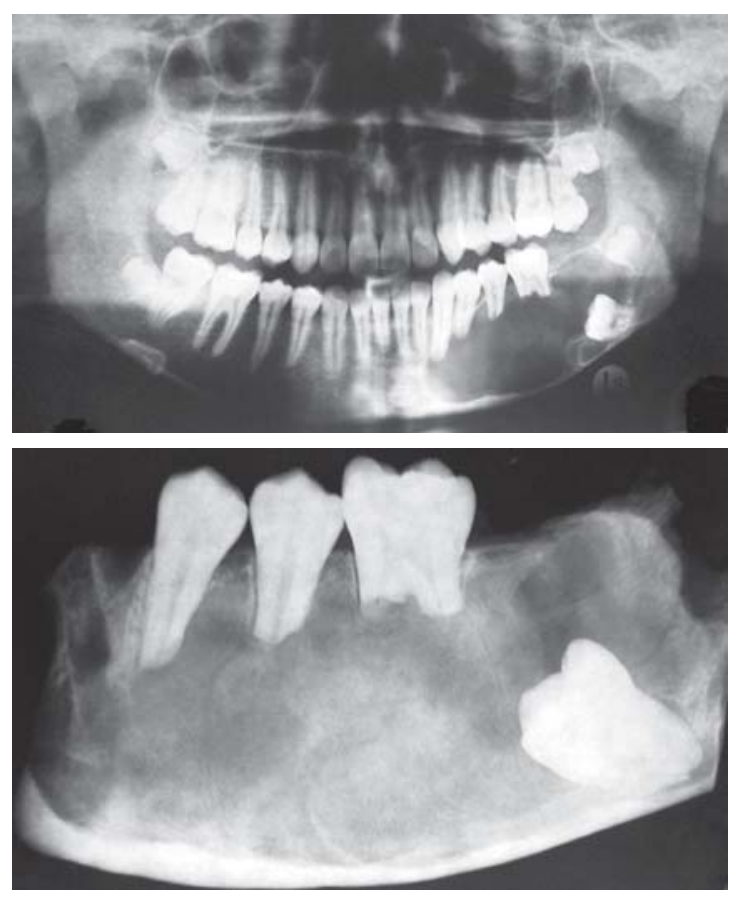

Figura 1 - Radiografia panorâmica demonstrando extensa área lítica, no lado esquerdo da mandíbula, com rizólises e retenções dentárias associadas.

Nota: Detalhe da peça operatória (tumor ressecado) em radiografia de controle. biópsia por congelamento, para verificar se as margens estão livres de células neoplásicas 5 . É sabido que as margens radiográficas do tumor não correspondem às margens histológicas. Isso vai de encontro ao proposto por Gortzak e colaboradores. ${ }^{6}$

Gomes e colaboradores 2 verificaram uma tendência menos invasiva das terapêuticas cirúrgicas, mesmo para o ameloblastoma multicístico. Porém alertase para a questão: o que é ser conservador? É submeter o paciente a numerosos procedimentos no decorrer da vida? Isso resulta em mutilação em longo prazo, de difícil reabilitação.

Já foi demonstrado que a recorrência ocorre, em média, após 5 anos, recomendando-se, então, a reconstrução imediata com proservação criteriosa, a cada 6 meses. Aliados a isso, os avanços tecnológicos e a melhoria das técnicas deram maior suporte ao diagnóstico, planejamento e tratamento. A utilização de tomógrafos e de ressonância magnética nuclear de última geração, tecnologia CAD-CAM-CAS (biomodelos de prototipagem rápida), a melhoria dos implantes osseointegráveis, cada vez mais, permitem aos cirurgióes planejarem e executarem melhores tratamentos do ponto de vista reabilitador funcional, o mais cedo possível.

\section{CONCLUSÓES}

Esta revisão permitiu conferir a persitente controvérsia, na literatura, quanto à abordagem cirúrgica do ameloblastoma. Ainda há muito a se investigar sobre essa patologia de comportamento biológico incógnito, para se chegar à uniformidade de conduta. Porém a maioria dos autores concorda que fatores tais como o tipo do tumor, as características histológicas e radiológicas, a localização anatômica e a idade do paciente são determinantes para a escolha da conduta cirúrgica a ser adotada. 


\title{
Surgical treatment of ameloblastoma: review of currente literature
}

\begin{abstract}
The treatment of ameloblastoma is one of the major controversies of Surgery and Traumatology Bucco-maxillo-facial, due to lack of information in the literature, as well as the large number of conduct imposed. Thus, we performed a literature search on the site www.pubmed.gov, being selected the articles published in 2006 related to the surgical treatment of ameloblastoma. With the objective to verify, discuss and clarify such conduct. Based on data obtained, there is controversy about many of ideal treatment, but most authors agree that fundamental factors such as the type and age of the patient are crucial to the choice of surgical conduct to be adopted.
\end{abstract}

Keywords: Ameloblastoma- Treatment; Odontogenic neoplasm.

\section{REFERÊNCIAS}

1 GHANDHI, D. et al. Ameloblastoma: a surgeon's dilemma. J. Oral Maxillofac. Surg., Philadelphia, v.64, p.1010-1014, 2006.

2 GOMES, A.C.A. et al. Conceito atual no tratamento dos ameloblastomas. R. Cir. Traumatol. Buco-Maxilo-Fac., Recife, v.6, n.3, p.9-16, 2006.

3 SAMMARTINO, G. et al. Effectiveness of a new decisional algorithm in managing mandibular ameloblastomas: a 10 -years experience. Br. J. Oral Maxillofac. Surg., Edinburgh, v.45, n.4, p.306-310, June 2007.
4 SACHS, S.A. Surgical excision with peripheral ostectomy: a definitive, yet conservative, approach to the surgical management of ameloblastoma. J. Oral Maxillofac. Surg., Philadelphia, v.64, p.476-483, 2006.

5 CARLSON, E.R.; MARX, R.E. The ameloblastoma: primary, curative surgical management. J. Oral Maxillofac. Surg., Philadelphia, v.64, p.484-494, 2006.

6 GORTZAK, R.A. et al. Growth characteristics of large mandibular ameloblastomas: report of 5 cases with implications for the approach to surgery. Int. J. Oral Maxillofac. Surg., Copenhagen, v.35, p.691-695, 2006. 